\title{
A BENJAMIN FRANKLIN, PADRE DE LAS LENTES BIFOCALES, EN EL TRICENTÉSIMO ANIVERSARIO DE SU NACIMIENTO
}

\author{
NOGUERA-PALAU $\mathbf{J J}^{1}$
}

Benjamin Franklin nació el 17 de enero de 1706 en Boston, décimo hijo de Josiah Franklin y Albiah Folger, su segunda esposa. Pasó unos pocos años en la escuela y enseguida comenzó a trabajar en la imprenta que dirigía su hermano James; cuentan las biografías de Franklin que quizá fuera allí donde se despertara su pasión por la lectura y por el estudio de las materias más diversas: así fue tipógrafo, escritor y editor, profundo conocedor de idiomas (latín, francés,

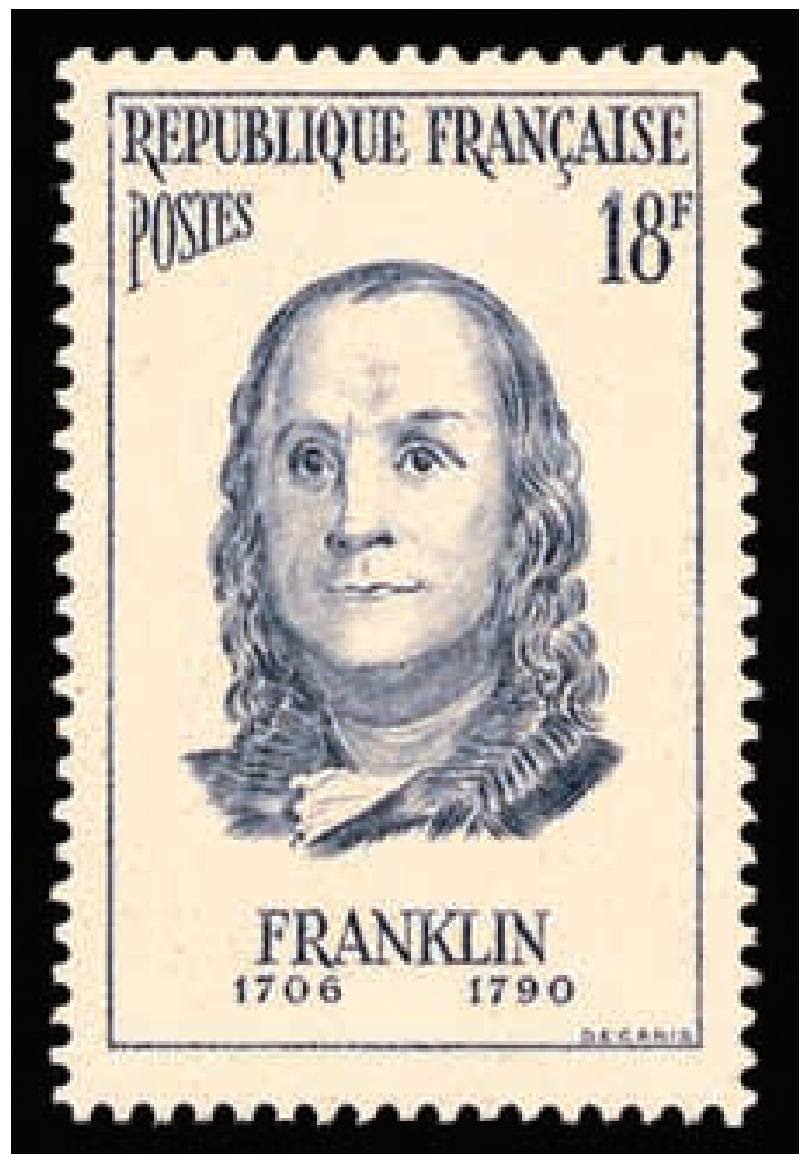

Francia 1956. Yvert 1082 (de 1082/87). español e italiano), reconocido físico e investigador sobre la electricidad, político, inventor...

A los 17 años se fue a vivir a Nueva York. De allí viajó a Filadelfia, donde trabajó como aprendiz en una imprenta hasta que logró la suya propia de la que salió la Gaceta de Pensilvania, publicación de información general y política en la que Franklin colaboraba con artículos y dibujos, y el Poor Richard's Almanack, un breve anuario que contenía información de los más diversos temas: recetas, predicciones del tiempo, noticias, reportajes y aforismos firmados por el «pobre Ricardo Saunders», seudónimo de Benjamin Franklin, quien justificaba la venta del almanaque para obtener unos peniques con los que cuidar a su malhumorada esposa.

En 1731 creó el primer gabinete de lectura de América. Fundó el primer cuerpo de policía y de bomberos, ordenó la pavimentación de las calles de Filadelfia y creó la Sociedad Filosófica y una Academia que luego se convertiría en la Universidad de Pensilvania.

En 1736 trabajó en la Asamblea Provincial de Pensilvania y fue director de los Correos de la Colonia Británica. Fue nombrado doctor por las universidades de Edimburgo, San Andrés y Oxford.

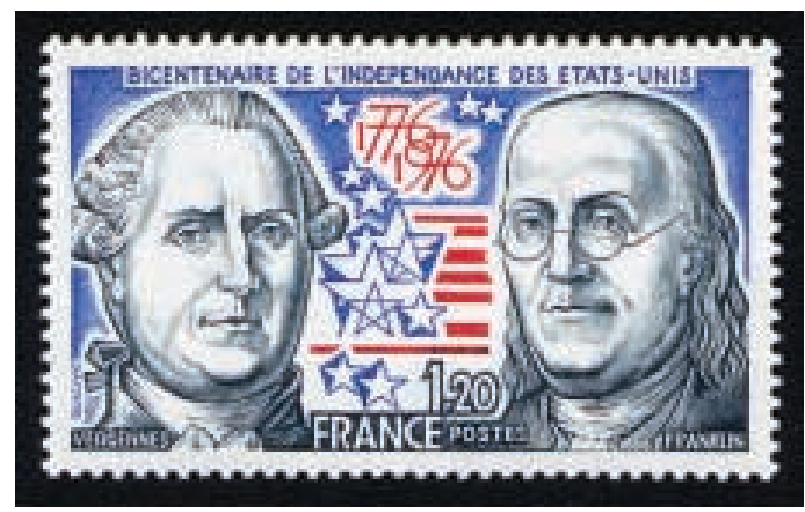

Francia 1976, Yvert 1879.

1 Oftalmólogo. Pamplona. España.

E-mail: jnoguera72b@terra.es 


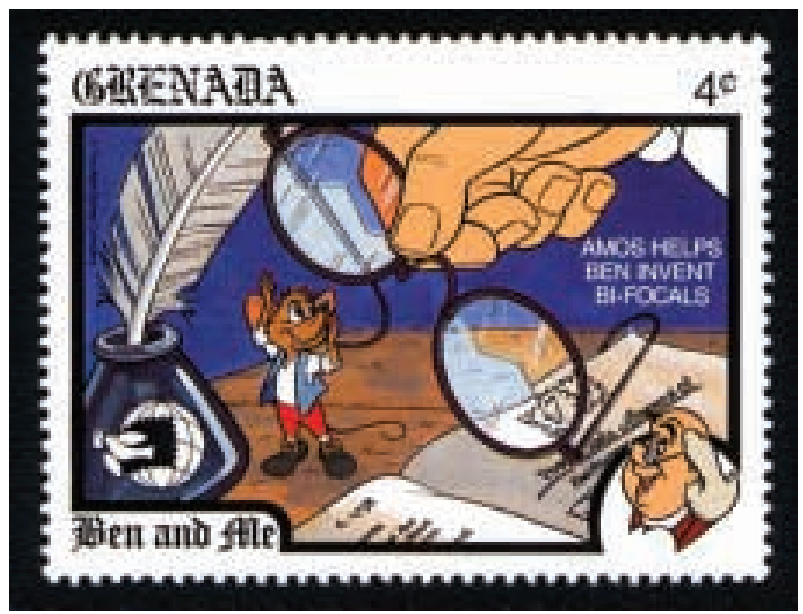

Grenada 1989, Yvert 1843 (de 1842/46 + HB 224).

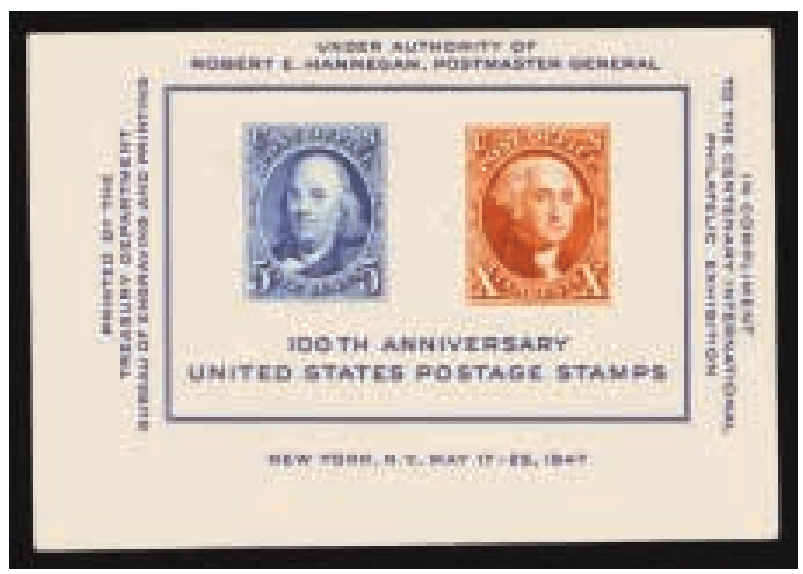

Estados Unidos 1947, HB 8 (de $499+H B 8)$.

Fue un destacado y perseguido luchador contra la soberanía de Inglaterra sobre su país y participó en la redacción del Tratado de Independencia de 1776. Desde este año hasta 1785 fue embajador de los Estados Unidos en París, en la corte de Luis XVI. En 1785 fue elegido presidente del estado de Pensilvania, cargo que ocupó hasta 1788 cuando se integró en la convención que elaboró la Constitución de los Estados Unidos. En 1789 publicó un tratado contra la esclavitud.

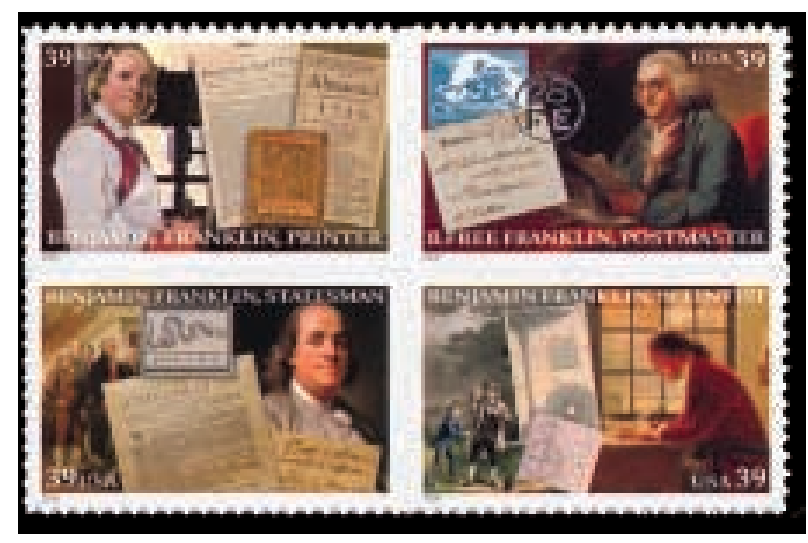

Estados Unidos 2006, Yvert 3770/73.

La actividad como inventor fue de lo más variopinta: a él se debe la primera sonda vesical que, al parecer, se fabricó en los Estados Unidos; un sistema de compartimentación de seguridad del fondo de los barcos; el pararrayos; una estufa que evitaba que las llamas de la combustión de la madera provocaran un incendio; un artilugio, llamado odómetro, para calcular las rutas de reparto del correo; una vara con una pinza en su extremo con la que alcanzaba los libros de los anaqueles más altos; unas aletas para nadar; la armónica de cristal, unos discos medio sumergidos en agua que, al hacerlos girar con un pedal y apenas rozándolos con la yema de los dedos, emiten un peculiar sonido... ¿Y para la oftalmología, qué? Las lentes bifocales que hoy conocemos como «modelo ejecutivo» son muy parecidas a las que en 1784 diseñó Benjamin Franklin, a quien universalmente se le considera el padre de estas lentes porque en aquel año había escrito acerca de ellas; sin embargo, parece existir una patente norteamericana extendida en 1783 a favor de Anderson Smith como primer creador de este tipo de lentes.

Nuestro personaje murió en Filadelfia el 17 de abril de 1790.

Son muchos los sellos dedicados en todo el mundo a Benjamin Franklin. De entre ellos ilustran esta nota los dos de los correos franceses, uno de los de Grenada y dos muestras de los numerosos editados en los Estados Unidos. 